\title{
Overcoming Obstacles to Education: The Experience of Women University Students Diagnosed with Attention-Deficit / Hyperactivity Disorder
}

\section{SONYA CORBIN DWYER}

University of Regina

\begin{abstract}
Much of the research on Attention-Deficit / Hyperactivity Disorder (AD/HD) has been conducted with male children, resulting in limited knowledge of the disorder in females and adults. Even though increasing numbers of students with the disorder are entering postsecondary institutions, $\mathrm{AD} / \mathrm{HD}$ in this population is an understudied area. A hermeneutic phenomenological methodology was chosen to explore the experience of eight women university students diagnosed with AD/HD. Two themes describing obstacles to their education, Robbed of Time and Thoughts Like a Rubber Ball, were identified. Strategies and treatment issues, implications for educators and mental health professionals, and directions for future research are considered.
\end{abstract}

This research was supported in part by grants from the Scottish Rite Charitable Foundation of Canada, through the Roeher Institute, and the Learning Disabilities Association of Canada. I would like to acknowledge the assistance of Dr. Marilyn Samuels, whose contribution included critiquing the manuscript. 


\section{RÉSUMÉ}

La plupart des recherches produites sur le déficit d'attention avec hyperactivité a porté sur des jeunes garçons, si bien que la population féminine et adulte a été négligée. Bien qu'un nombre croissant d'étudiants souffrant de ces troubles fréquentent les institutions postsecondaires, ils font l'objet de peu d'études. Nous avons choisi une méthodologie phénoménologique herméneutique afin d'analyser les expériences de huit étudiantes d'université souffrant d'un déficit d'attention avec hyperactivité. Deux thèmes ont été identifiés décrivant les obstacles à leur éducation: Le temps volé et Des pensées comme des balles de caoutchouc. Des questions de stratégies et de traitement, des implications pour les professionnels de l'éducation et de la santé mentale, ainsi que des orientations de recherches futures sont examinées.

College and university students with disabilities often encounter barriers to their education, including a lack of understanding and cooperation from administration, faculty, staff and other students, and a lack of adaptive aids and other resources (e.g., West, Kregel, Getzel, Zhu, Ipsen, \& Martin, 1993). Attention-Deficit / Hyperactivity Disorder (AD/HD) in the college population is a vastly understudied area (Weyandt, 1995) even though increasing numbers of students with the disorder are entering colleges and universities (Richard, 1994). Current research indicates that women perceive the academic climate to be chillier than men do, which includes finding university to be an inhospitable environment and reporting general dissatisfaction with the quality of their education experience (Seagram, Gould, \& Pyke, in press as cited in Pyke, 1997). Women university students with $\mathrm{AD} / \mathrm{HD}$ may be experiencing even more obstacles in getting an education because they are female and have $\mathrm{AD} / \mathrm{HD}$.

Before proceeding, it is necessary to clarify the terms ADD and $\mathrm{AD} / \mathrm{HD}$ as both are currently used by clinicians. Brown (1995) noted that most of the early diagnostic descriptions of the disorder focused on the hyperactive behaviour of "disruptive children" (p. 93). He explained that this was the case until research indicated that most of these children had impulsive and inattentive characteristics in addition to hyperactivity. For many years, these three characteristics were considered to define the 
disorder; today some educators, doctors, and parents still consider a diagnosis of $\mathrm{AD} / \mathrm{HD}$ only if all three symptoms are obvious (Brown, 1995).

It was not until the publication of the DSM-III in 1980 and the inclusion of the term Attention Deficit Disorder that the term "ADD" could be used to label children with or without hyperactivity. However, when the DSM-III-R was published in 1987, there was still a lack of research to support the notion that the disorder may occur without hyperactivity and hence, the diagnosis was renamed Attention-Deficit Hyperactivity Disorder. The previous diagnosis of ADD W/O that was used to designate "without hyperactivity" was replaced by Undifferentiated ADD. This new label had no diagnostic criteria, and thus called into question the validity of this diagnosis. However, since that time, many research studies have documented $\mathrm{AD} / \mathrm{HD}$ with and without hyperactivity and, as a result, subtypes of AD/HD in the DSM-IV (APA, 1994) include Predominantly Inattentive Type (Brown, 1995).

Adult women constitute the most rapidly growing section of the student population (Hayes \& Flannery, 1995). Yet, these authors noted, there is little work on women's learning in higher education. This is due in part, they explained, to much of the research having been conducted on the learning of girls and adolescent females and then extrapolated to adult women. Characteristics of adult women students are changing, along with societal norms and expectations that may affect their education. In order to study women's learning, researchers therefore need to know what kind of information is relevant to this understanding. One place to start is with an awareness of the social contexts in which women's experiences occur and the personal or emotional meanings women give to their experiences (Laidlaw \& Malmo, 1990).

This study focused on women diagnosed with $\mathrm{AD} / \mathrm{HD}$ enrolled in university. $\mathrm{AD} / \mathrm{HD}$ in adults is still a relatively new area because clinicians believed for decades that the symptoms disappeared in adolescence. While there is still debate over its prevalence in adulthood (Fischer, 1997), it is now generally accepted that AD/HD can be a lifelong condition (Weiss, 1992). Adult women were chosen for this research because the number of females being diagnosed with $\mathrm{AD} / \mathrm{HD}$ is rising and most research on $\mathrm{AD} / \mathrm{HD}$ has been conducted on male children. This has 
resulted in limited knowledge of the disorder in other populations, particularly females and adults (Schaughency, McGee, Raja, Feehan, \& Silva, 1994). While some practitioners are recognizing that women with $\mathrm{AD} / \mathrm{HD}$ have different experiences than men with the disorder because of the socio-political context in which they live (e.g., Solden, 1995), much of the current information about women who are diagnosed with $\mathrm{AD} / \mathrm{HD}$ is anecdotal, based on clinical observation.

\section{METHOD}

Hermeneutic phenomenology was chosen as the most appropriate methodology to help answer the question "What is the meaning of the lived experience of women university students diagnosed with AD/HD?" The purpose of hermeneutics is to try to 'grasp' the essential meaning of the phenomenon by questioning what something is 'really' like (van Manen, 1990). According to phenomenology, reality is understood only in the form in which it is perceived and meaning comes from the interpretation given to it by a person (Stainback \& Stainback, 1988). This approach can permit the research process to be an exchange of perception and interpretation that allows the women to participate actively in the description and interpretation of their existence. Hermeneutic phenomenology is concerned with description and with interpretation. I will now briefly describe the methodology of the hermeneutic phenomenological approach.

\section{Hermeneutic Phenomenological Approach}

Hermeneutics as a research method is a way of systematically dealing with interpretation (Bolton, 1987). van Manen (1990) explained hermeneutic phenomenological research as the study of lived experience; the explication of phenomena as they present themselves to consciousness; the study of essences; the description of the experiential meanings we live as we live them; the human scientific study of phenomena; the attentive practice of thoughtfulness; a search for what it means to be human; and a poetizing activity. The goal is to obtain fundamental knowledge of phenomena and the meaning of Being since 
understanding and possibilities are the consequence of interpretations (Cohen \& Omery, 1994).

Hermeneutic phenomenology is "the study of essence - what makes something what it is" (Ray, 1990, p. 173). As Bergum (1991) explained, the hermeneutic phenomenological approach is concerned with the description of the experience and with the act of interpretation as a way of pointing to the nature, or essence, of the phenomenon. To more deeply understand the experience, the researcher must be involved in a dialogue between her inner passion and outer activities (Bergum, 1991).

In hermeneutics, Kvale (1996) explains, "The understanding of a text takes place through a process in which the meaning of the separate parts is determined by the global meaning of the text, as it is anticipated" (p. 47). The discovery of the meaning of the separate parts may lead to changing the anticipated global meaning, which in turn influences the meaning of the separate parts, and so on. This can be an infinite process so it ends when the researcher has reached " a sensible meaning, a valid unitary meaning, free of inner contradictions" (Kvale, p. 47). Guba and Lincoln (1989) asserted that hermeneutic philosophy maintains there are multiple, socially constructed realities and 'truth' is a consensus constructed from the amount and quality of information and the degree with which the information is understood and used. Hermeneutic methodology involves a continuing dialogue of iteration, analysis, critique, reiteration, reanalysis, and so on until a joint construction of meaning emerges among the researcher and participants (usually via their transcribed conversations) (Guba \& Lincoln, 1989).

This section attempted to identify the essential qualities of hermeneutic phenomenology, the method of inquiry dictated by the research question.

\section{Participants}

The number of participants selected for a hermeneutic phenomenological study varies considerably (Polkinghorne, 1989) and depends on saturation. Saturation is the collection of data until no new information is obtained and is evaluated by the researcher on the adequacy and comprehensiveness of the data (Morse, 1995). One of the principles of saturation 
in qualitative research is to select a cohesive sample. Women volunteers were selected based on the following criteria: they had to be twenty years of age or older, presently enrolled in university, diagnosed with ADD or $\mathrm{AD} / \mathrm{HD}$ (either of the three subtypes) by a psychologist or psychiatrist either in childhood or adulthood, currently experiencing difficulties with attention, impulsiveness, and/or hyperactivity, and able to articulate their experience (Osborne, 1990, 1994). Saturation was determined to have been reached after interviewing the eighth participant.

Each woman's story presented briefly here is reconstituted from our conversations about their experience. Some demographic details as well as the themes that pertain to each woman's individual experience are described. The women are presented in no particular order. All of the participants in this study used the term ADD, therefore it will be used throughout the remainder of this paper to reflect its use by the women. I, as writer/researcher, am also involved in the study and who I am affects my interpretation of the women's experience. Therefore, I will briefly introduce myself first.

\section{Writer/Researcher}

I first became interested in finding out more about adults who exhibit characteristics known as ADD while working as a psychologist in private practice. Having previously worked as a school psychologist, I was much more familiar with children with ADD, almost all of whom were hyperactive. When I began to search the literature on adults and $\mathrm{ADD}, \mathrm{I}$ found there was a paucity of information.

When I later became a doctoral student in the Department of Educational Psychology, I was interested in studying factors that affect learning. This included identifying the needs of students and strategies to effectively address those needs. In order to effectively assist students, we must be mindful of their experience, from their perspective.

Combining these two areas with my interest in women's psychology led me to be drawn to the topic and to this population.

\section{Robin}

Robin ${ }^{1}$ is a twenty-five year old, third year undergraduate student. In the year prior to the first interview, she was diagnosed with dyslexia and 
ADD, the characteristics of which she views as one and the same. As a child, Robin was hyperactive but she has since grown out of the hyperactivity. Thinking of her diagnoses as more of a learning style, she is concerned about the accuracy of the term "Attention-Deficit / Hyperactivity Disorder." She dislikes the label because of the negative connotations of having a "disorder," preferring to explore a person's strengths and weaknesses rather than simply use a label.

Robin does not consider medication an option for her, relying instead on behavioural coping strategies she has gleaned through personal observation. For example, she has chosen to live alone because it is quieter and helps her to focus. She has learned a number of strategies that she uses with regard to academic work, including the accommodation of writing exams in a private room and choosing professors that suit her learning needs. Interested in alternative treatments, Robin reads many books on the topic.

Robin thinks that people with ADD characteristics should be seen as "different" and not as "wrong." Recognizing the emphasis in our society to conform, she asserts that people should not all be the same because she believes that all individuals have gifts.

\section{Dagny}

Dagny, age twenty-one, is in her fourth year of an undergraduate degree. She was diagnosed with ADD at age six although she did not personally become aware of it until about age eighteen. Growing up she came to the conclusion she was stupid because it would take her twice as long as her classmates to complete her work, and her work would not be as "good" as that of her peers. She became very discouraged and passive, which, she noted, she grew out of. She describes herself as a private person and commented that her mother did not know how much she struggled in high school because she would retreat to her room rather than talk to her mother.

Dagny tries not to take her medication regularly. The reasons for this include wanting to be "normal" and hoping she can perform efficiently without it. As well, the prescriptions her doctor writes for her are only sufficient for three days at a time, so she takes the medication when she finds it absolutely necessary. For example, she was worried 
about interacting with her co-workers at her summer job, especially in conversations, so she would take her medication before meeting with her supervisor. She has asked her professors for help in the past but she did not receive what she needed mostly because she felt they did not understand ADD. She prefers to work things out on her own now. She sets goals for herself which she is determined to achieve. She sees ADD as something to "fight" because it could take her rewards away from her.

Dagny has found the information available on the Internet on ADD as both comforting and useful. On the Internet there are an abundance of personal stories written by people with ADD that provide Dagny with much strength since she does not feel as alone when she reads them. She also gives these stories and other information to her boyfriend to read so he can better understand her.

\section{LJ}

LJ is in her mid-thirties. At the time of the first interview, she had been diagnosed with ADD for about a year and was a university student taking some graduate courses as an unclassified student. She has already earned two undergraduate degrees, one of which is a professional degree. After completing the second degree, LJ was employed in her field. In retrospect, she says she chose to quit this job because of the ADD symptoms, although she was unaware she had the disorder at that time.

During the course of the present research, LJ became enrolled in a diploma program at a technical institute that she planned to use in conjunction with her second degree. The road to the diploma program was not an easy one for $\mathrm{LJ}$ and she sought a vocational assessment to help her with choosing a career. She has come to the realization that she does not want a job that keeps her in an office five days a week but would prefer to be out in the field, with a more hands-on approach. Another psychologist she consulted about ADD is a significant part of her support system. LJ feels she relies on others' opinions because she often does not know what she thinks or how to listen to what she thinks.

LJ does not consider herself to be a typical person with ADD. She does not feel she has done poorly academically, although her performance has been very uneven and inconsistent. Her advisors for both of her degrees 
indicated to her that she was not putting any effort into her work. $\mathrm{LJ}$ is currently trying medication as part of her treatment and finds that it is helping.

\section{Michelle}

Michelle is thirty-seven years old and was diagnosed with ADD within the a few months prior to the first interview. She describes herself as having a "sporadic, interrupted university career." Michelle went to university after high school but did not achieve the high marks she expected based on her secondary school achievement. This caused her to question her ability and to generate possible explanations. Michelle thought that since she is a woman of color, perhaps her high school teachers had pushed her through, not wanting to be perceived as discriminatory, a type of reverse discrimination. She dropped out of university after one and a half years and, for approximately two years, worked in a variety of jobs that she did not enjoy. She then went back to university and completed an undergraduate degree. After applying to one graduate program and not getting accepted, Michelle obtained a summer job and returned to university to improve her marks to get into a professional faculty. She did not get into this faculty and went to work full-time. She decided she really did not enjoy that work and returned to university again to upgrade her marks. After a couple of years, she found that she had almost enough credits for a second degree. She proceeded then to add up the courses she had in each faculty to see which area she needed the least number of courses in for a major. She was completing this second degree when we initially talked.

Michelle described her academic performance as "hit and miss" because her achievement was so unpredictable. If she gets along with a professor or finds the professor stimulating and is interested in the subject, she does well. As well, she has been battling depression "ever since [she] can remember." Michelle feels a good support network of friends with similar interests to her own has really helped her be successful in university.

\section{Christine}

Christine is a forty-one year old, divorced single-mother of two children, both of whom are diagnosed with ADD. She is in her fifth year of 
an undergraduate degree. She was diagnosed with ADD about three years prior to the initial interview, as a result of her children being diagnosed. She described her initial reaction to her diagnosis as feeling overwhelmed and devastated, as well as feeling guilty that her children inherited the disorder from her. She did research on ADD for a course she took in university and this research helped put things into perspective for her. She has come to terms with the diagnosis and tries to focus on the positive. While she focuses on the positive, Christine knows there are negative aspects to ADD symptoms. However, she says it is sometimes easier to blame things on the ADD than it is to take responsibility for a person's actions.

Christine enrolled in university for the first time after working in one particular field for many years because she was not being recognized in her job. She found the two faculties she has taken the most courses in to be very supportive. Her experience with professors has also been positive as she finds them nonjudgemental and accepting. She describes herself as having many, many interests and finds it difficult to make up her mind, changing her mind about faculties a few times, sometimes questioning whether her last change was impulsive. She sets high goals for herself and sometimes questions whether they are achievable or realistic. Christine feels that she needs to work in a positive environment because she would find it difficult to not bring the negative issues home with her, to dissociate herself from that aspect of a job.

Christine personally finds medication tremendously helpful, and described the first time she tried it as her "whole world" coming into focus. However, a side effect of too much medication is aggression, intolerance and impatience. When Christine started university, she did not have any study skills. She has since developed many of her own, modifying or changing them as required.

\section{Suzie}

Suzie is twenty years old, in her second year of university. She was diagnosed with ADD when she was sixteen. The diagnosis facilitated a deeper self-understanding of her actions and motivations and also helped Suzie to change her behaviour. Initially, Suzie was not aware that ADD affected areas of her life other than learning. She has always had and continues to have social difficulties, particularly with relationships and 
making friends. Having a quick temper, she reacts quickly to others but sometimes her interpretation of their actions is inaccurate. She realizes she reacts impulsively to others. Her parents, who are her main support system, are helping her become more aware of these situations.

Suzie feels that she learns faster than most. However, once she has mastered a topic she then finds herself easily distracted. She now looks ahead at what her professors will be discussing to help her stay interested. She feels as if she sees things from a different perspective than most people and this enables her to make connections that other people do not see. She believes she is smart but academically her performance has always been lower than what she feels she is capable of achieving. She has a lot of difficulty with test-taking. She learns from doing, applying what she is taught. She has received a lot of tutoring in learning strategies from her psychologist.

Suzie enjoys the freedom of university because she can make choices. She feels her faculty is very suitable for her ADD characteristics. However, she perceives that she has to achieve things by "sneaking in the back door," such as getting into university and her faculty because her marks do not reflect her ability. She questions whether she is good enough to walk in the front door. Even though she met entrance requirements when she was admitted by the "normal route," it often does not feel "normal" to her.

\section{Dawn}

Dawn is in her mid-twenties and her second year of university. She was diagnosed with ADD a year before we met. Initially Dawn did not think she was smart enough for university but she went to prove to herself that she was. She found that she studied all of the time and had no social life. Although Dawn worked really hard and got ' $B$ 's, she felt she was not living up to her potential and could do better.

She is not satisfied with the assessment process as she perceived that too much weight was put on "one bad" day of a two day assessment. As a result, she is not really convinced of her diagnosis. Part of her does not believe it and part of her wants to believe it because it would explain her difficulties with school. Therefore, the diagnosis did provide a little 
relief as the cause is not a lack of ability. She does not feel she has a severe form of the disorder.

A lot had changed for Dawn by the second interview. Her medical doctor became angry with her for missing appointments so she found another doctor. She finds the new doctor much more understanding of her difficulties. He prescribed Ritalin instead of the Dexedrine she was taking before because she did not find that Dexedrine really helped. The Ritalin has helped her make many positive improvements. As well, he increased the dosage of the medication she is taking for depression and recommended exercise and taking fewer courses. She was working parttime and reduced the number of hours she worked. She feels the results of implementing these changes include using her time more efficiently and effectively, taking time for herself by reading for pleasure, and enjoying a social life which did not exist before.

Dawn believes there is a social stigma about having ADD. She wishes there was some conclusive way to test for ADD, such as a blood test. She knows people with similar difficulties and wonders if and how the assessment process accurately distinguishes between those with ADD and those who exhibit similar characteristics.

\section{Sue}

Sue is in her late forties and is a divorced, single-mother of two children. She was diagnosed with ADD a couple of years ago after her oldest child was diagnosed with the disorder. Sue completed an undergraduate degree in the mid-1970s and has just returned to university where she is now enrolled in a diploma program. She is really enjoying university this time as she understands herself and her needs better because of the diagnosis. For example, she finds that her hands do not move quickly enough to keep up with her thoughts and now she has strategies to deal with this issue. As well, during her first degree, Sue spent all of her time studying, having to work ten times harder than her peers but back then she did not know why.

Medication for ADD is not an option for Sue because she has sensitivities to medication. As a result she looks for other ways to help her focus. For example, she finds she works well with a coach. Sue has difficulty changing modes and feels that once she is out of the house, she 
may as well keep on moving since she finds she cannot go back to the house and resume the activity that she has left. The diagnosis helped her put her need to be busy into perspective. She always seemed busier than most people in all facets of her life

Sue has never had time for friends. When she was in university the first time, she did not have a social life because she did not have time, she was always studying. Later, she became a single mother and worked fulltime. She has always felt alone and lonely. She has felt like a "square peg in a round hole" her whole life and she does not feel understood by her family. A relative once commented that it seemed as if Sue and her brother were from different planets, not the same family. After she became diagnosed, she joined a group with other adults diagnosed with ADD. The group really helped increase Sue's self-esteem because the other group members experienced the same "weird" things that she did, so she no longer felt as alone. As well, she enjoys talking to people with ADD characteristics because she finds them so dynamic in their thinking. However, people without ADD qualities tend to keep her grounded.

\section{Interview Process}

To assist my participants in reflecting on their experience and to determine deeper meaning, three interviews were arranged to allow for reflection on previous interviews (van Manen, 1990). Each participant, with the exception of one, was interviewed individually on two separate occasions. The purpose of the second interview was to provide the women with an opportunity to read the draft description of the phenomenological themes so they could be starting points for further sharing about the nature of the lived experience (van Manen, 1990). At the beginning of this interview, I presented each woman with a summary of the topics she had discussed in the first interview. In addition, I surveyed the recurring topics from all of the conversations and shared this information with them. Then the women were asked to speak to whatever topics they wished to explore further. This reflection was an opportunity for the women to generate deeper meanings of their experience. Each interview was approximately seventy-five minutes in length. The interview sessions were audiotaped for later transcription. Participants were 
offered the option of participating in a third interview. This interview was a means to account for the quality of the study. It was an opportunity to see if my thematic analysis resonated with their experience.

One participant, Robin, left the country after the first interview and could not be located by telephone, postal service, or electronic mail. When she returned to university, the second interviews had been completed, transcribed, and the thematic analysis was partially completed. It was decided that a 'second' individual interview would not be conducted with Robin but that the data from her first interview would be included in the research. Robin's first conversation complemented those of the other women and made a valuable contribution to the collaborative hermeneutic conversation. As well, Robin did participate in the 'third' interview in which I presented my metaphorical analysis. This interview also allowed her to reflect on her experience, for more interpretive insight.

An interview is an exchange or sharing of views between two people discussing a topic of mutual interest (Kvale, 1996). For the most part, the initial interview was minimally structured and open-ended. I began with the question "what is your experience as a woman university student diagnosed with Attention-Deficit / Hyperactivity Disorder?" Participants were encouraged to discuss their experience from a point where they wanted to begin.

So that the material gathered using this approach did not become unmanageable, it was important that I be oriented to my question so the interview did not "go everywhere and nowhere" (van Manen, 1990). One way of staying close to the participant's lived experience was to be very concrete and to ask the women for specific examples.

As researcher, I asked clarifying questions as they arose and used active listening skills such as paraphrasing and reflecting. When I had no further clarifying questions, the participant was asked if there was anything further she wanted to discuss or ask about (Kvale, 1996). When the participant had nothing further to say, I concluded the interview by mentioning some the main points I learned from our conversation (Kvale, 1996). If the conversation continued after the audiotape recorder was turned off, notes were taken. All tapes were coded with a number and the transcripts were identified using the participant's pseudonym. 


\section{Thematic Analysis}

To avoid prejudging the data, I acknowledged, and attempted to suspend, preconceived notions about the phenomenon, especially during the generation and early analysis of themes. I attempted to make explicit and explore my presuppositions in the form of a journal (Ray, 1990) and account for my decision-making process (Lloyd, Ennis, \& Alkinson, 1994). As well, potentially important ideas, concepts, and themes were identified by writing down recurring ideas, questions, and thoughts in the journal during the entire process (Maykut \& Morehouse, 1994).

Analysis is interwoven with data collection. Because analysis is the product of an inductive and emergent process, a description of the process does not entirely capture what goes on (Lofland \& Lofland, 1995). Intuition is important in the process of reflecting on the data and in grasping the essence of the phenomenon (Ray, 1990; van Manen, 1990). The goal is to arrive at an understanding of lived experience that is both rigorous - based on systematic observation - and imaginativebased on expressive insight (Ellis \& Flaherty, 1992). As van Manen (1990) asserted, thematic understanding is not a rule-bound process but a process of insightful discovery, "a free act of "seeing" meaning" (p. 79).

I engaged in reflective analysis by listening to audiotapes and reading the transcribed conversations several times. I practiced one of van Manen's (1990) approaches to isolating themes in text, the selective or highlighting approach, to assist with my reflective analysis. As I listened and read, I asked myself "What statement(s) or phrase(s) seem particularly essential or revealing about the phenomenon or experience?" (p. 93). I then highlighted these statements.

The working themes were arranged on a large sheet of paper to visualize the relation among them (Lofland \& Lofland, 1995) and posted in a room where most of the data analysis took place. Extracting themes from the data invited me to go back and ask more questions of the data. This is partially what it meant by the analysis process not being a linear one. Tesch (1987) describes it as more of a "cycling and spiralling", the reason why researchers have to be immersed in their data. 
Once the themes and data were revisited several times, and I felt I had a consensus on the 'experience,' I turned to the data again to find examples of this interpretation. I extracted some features of the phenomenon that helped make it 'visible' (van Manen, 1990) by asking the following questions of the data: Of what aspect is this an instance? What questions about an aspect does this item of data suggest? What sort of answer to a question about an aspect does this item of data suggest? (Lofland \& Lofland, 1995). Sometimes the examples were used to show how the phenomenon differs from other phenomena as well as to demonstrate the appropriateness of the themes that I have identified (van Manen, 1990).

During this phase of analysis, I listened closely to the women's voices and what they had to say about their lives and their experiences. Examples of the types of questions I asked of the data were: What are the recurring words, phrases, and topics? What are the concepts participants use to capture their experience? (Maykut \& Morehouse, 1994). Many of the women used metaphors in our conversations. My interpretation of their experience often pointed to the women's own words, their metaphors. Metaphors provide "ordinary access to extraordinary thinking that we may not yet have tried" (Miller, 1991, p. xvii).

\section{Hermeneutic Phenomenological Reflection}

Four metathemes emerged from the data, describing the essence of these women's experiences: Robbed of Time, Thoughts Like a Rubber Ball, Is ADD Real or Manufactured, and Janus-Faced (Dwyer, 1998). Only the themes most related to the women's experience in university will be presented here.

Although the two themes, Robbed of Time and Thoughts Like a Rubber Ball, are presented as discrete, they were in actuality intertwined throughout the women's stories of their experience (McEvoy \& Daniluk, 1995). As well, for the purposes of this paper, I will highlight aspects of each of these two themes as they pertain to the women's experience of acquiring a postsecondary education.

\section{Robbed of Time}

The women described being "robbed of time," never having enough time to accomplish the things required of them. These might include 
such things as: studying as much as they need or want to; completing tasks; or organizing. Dagny explained: "In my second year, my GPA dropped down because the courses increased in difficulty so I didn't have as much time to cover the information." LJ said that the "...noticeable impact [ADD] has is definitely on your study skills and your ability to organize and kind of put yourself on a timetable for things like papers... I end up studying the night before the exam...and...doing my paper the night before it's due." "I used to get really ticked off at people who used to...read the book three days before going in and they'd get 'A's and I'm thinking... 'how did you do that?'...I used to spend a lot of time doing this...I know I work harder than they do and that's very frustrating to me," expressed Christine. Michelle explained that she always submitted her first draft "because I never had enough time" since, in her words, "time always gets away from me."

These women expected to be like their peers in terms of the length of time required to complete tasks. Dagny presumed that she should only have to put in the same amount of time: "I shouldn't have to study six hours every night, none of my peers do it and they still get good grades...I can no longer go through taking twice as long to do things...I have twenty-four hours in my day, like they do." For Dawn, time is a major factor in planning her education: "Should I take three or four [courses]-this is a big decision for me."

Too often these women have been blamed for their difficulties, which led to them believing that they are to blame, particularly before they were diagnosed with ADD. LJ said: "People say...'you're not trying, try harder...you don't put any effort into what you do'... so you feel guilty because you don't understand what it is." Suzie commented: "I was tired of people telling me I wasn't trying hard enough." Michelle explained: "I was always struggling to meet a deadline...so I'm thinking 'well, if I can't get anything better then it's because I'm lazy'." Dagny no longer explains her disorder to professors because she does not feel understood: "I don't share [the diagnosis] with professors because in general... a lot of them don't know much about it, they don't understand it, and again it would be 'you just need to work harder. It's an excuse.' That's how they see it." In his book, Blaming the Victim, Ryan (1971) discusses how 
norms (time limits in this case) in our society are taken for granted without any efforts being made to examine their purpose and usefulness. As well, no thought is given to the ways in which the norms (time limits) might themselves contribute to the development of the problems experienced by people who have been diagnosed with ADD.

More than one change in their way of approaching tasks is often required for these women to see their results equal their effort. These women demonstrated that the approaches they take may be as individual as they are.

\section{Thoughts Like a Rubber Ball}

Dagny used the analogy of a bouncing rubber ball to explain the difficulties she encounters when she tries to study. Her thoughts, like a rubber ball, may change direction abruptly and without warning. She describes this in the following words: "Your mind is at a very accelerated rate, kind of just zooming through life and just zooming through thoughts and ideas, usually which are not related to what you're doing." As a result of this kind of thought pattern, organizing information for written assignments can be difficult for these women. Undergraduate students at the university are required to pass an Effective Writing Exam. Suzie recounted this experience: "With that exam, reading it one time I didn't pass it, I saw exactly where I had changed thoughts and I literally went 'period, change thoughts' on the page...they just kept saying that I was unclear or I babbled."

The women's non-linear thought pattern described by the bouncing rubber ball analogy has a profound effect on their academic performance. Remarked Sue: "In doing assignments, my mind races along at an incredible speed and I can't get my handwriting to work as quickly...because my mind is racing, my hands don't move quick enough to write." Said Dawn: "I can't focus long enough to retain things [when reading]... if the sentence is really long, I've lost the concept by the end of the sentence. Studying...takes me so much time, I get sidetracked by anything." Dagny described her lecture experiences: "You hear everything but you don't really hear anything... You don't hear anything on a focus level but you're very aware of everything going on around you...you're not following any thought. That's probably one of 
the greatest problems with $\mathrm{ADD}$, to try and stay on one channel and to follow it on a continuance. That's very much a struggle." Dawn commented: "My mind used to wander a lot... at the lectures I found it difficult to keep up with the prof. I was always on his last words. I was constantly getting lost."

Once the thought, like a rubber ball, is in motion, the women can seldom predict where it will go or how long it will travel, making it difficult to catch. The thought moves so quickly that the women often find it difficult to remember how they arrived at the present location. On the other hand, watching a rubber ball can uncover new and exciting discoveries. However, the structure of our present educational system does not readily embrace deviation from the norm (in this case, non-linear thought patterns), and the results are then defined as failure to learn the rules (Ryan, 1971).

The effect on the women's education of having thoughts like a rubber ball is not the same for each one, as each of the women described different ways in which her thought pattern affects her ability to perform academic tasks. It is important to understand the learning styles of each individual, and not assume that ADD affects each person in the same manner.

\section{Overcoming Obstacles to Education}

While identifying barriers to education that they experienced, these women also discussed ways in which they attempted to overcome these obstacles. The first step in the process is being diagnosed with the disorder. With this new explanation for their behaviour, feelings of guilt over perceived lack of effort, internal character flaws, or feelings that their achievements are fortuitous are alleviated. LJ: "I have a lot of guilt about not going [to class] because you don't know why you're not going or why you hate to sit...I assumed that the problem... was due to a lack of maturity or adjustments...now I understand why I did." Michelle: "The last couple of years have been so satisfying for me...producing really, really good work and not have to feel like a fluke." New self-awareness about their learning styles puts an end to old interpretations. Robin said: "For the first time in my life, I'm realizing that I do things differently, have different learning styles than the norm. It never occurred to me that not 
everyone could do that...so just to be aware of that." Michelle explained: "It takes a lot of pressure off in terms of thinking of myself as a lazy person or not a lazy person. Now it's in terms of this is how I work."

The second step to overcoming obstacles to education is for women to uncover what they must do to achieve academically. They may find out through trial and error what works and what does not work for them, or they may consult a professional such as a psychologist. Paradoxes may arise when a woman knows what she must do to achieve academically but dislikes it all the same. In the first interview LJ told me: "You need to have a certain amount of structure in order to be successful. With ADD it has to be imposed somehow. It doesn't just come internal...I know that I function better where there is some kind of structure." Then in the second conversation she said "I hate [structure]...I'm just experiencing it and I don't like it any better. I can see how it helps, but I really hate it."

To remedy the time they do not have, these women use learning strategies, often discovered on their own. "You're looking for a way to not necessarily work less, but a way to do it more efficiently," explained Dagny. Christine said: "By reading [the text] out loud, that sort of brings me up equal with [my peers]." Michelle has a friend who acts like a coach and helps her with assignments by telling her: "OK, enough research, time to start organizing."

Accommodations for the classroom are another way to help these women deal with their difficulties. Christine explained: "What I find I need is a little bit of extra time for exams because when you ask me a question, there's no magical solutions to me...I'd say I have so many things come up at the same time that it takes me double that time [than it takes someone without ADD]." The issue of accommodations is a little more complex as it requires the cooperation of professors and administration. Nevertheless, by changing their environment, sometimes in very minor ways, these women are able to achieve to the level of their expectations. However, some of these women were unaware of the resources available to them on campus so were unable to avail themselves of accommodations.

Another option some of the women chose to use is medication, particularly Ritalin and Dexedrine. Michelle described the effects it had for 
her: "I've only been taking [the medication] for about a week and interestingly enough, probably for the first time in my life, I started and completed a project in one day...normally I wouldn't have done that. I might have left it for another day and that other day may never have come along because I've got this box full of projects that I have started." Dawn: "This Ritalin seems to be controlling a lot of my symptoms so I don't spend twenty minutes just organizing myself to start studying. I'm like 'open book, let's go' so I'm actually doing more studying...I don't study all of the time like I used to."

\section{DISCUSSION}

This study's findings are not intended to promote the needs and experiences of women as universal (Kaschak, 1992) but to make visible the varying experiences and perspectives not available in ADD research. Nor are the findings intended to serve as generalizations to all women diagnosed with $\mathrm{ADD}$. The purpose is to complement the existing literature as well as to extend the knowledge of the lived experience of women university students diagnosed with ADD. This study may assist women who are diagnosed later in life or who have symptoms but are not yet diagnosed by helping to increase their understanding of their own experience. Understandings generated from this study may assist educators interested in improving services for students at the postsecondary level.

Another reason for undertaking this study is the need for research to help develop a better understanding of clinical indicators of ADD in females (Biederman, Faraone, Spencer, Wilens, Mick, \& Lapey, 1994). Under-identification and under-treatment of females with ADD may have substantial mental health and educational implications (Beiderman et al., 1994). While the core symptoms of ADD may change over time, most of our knowledge is based on studies of elementary-school boys with the disorder (Cantwell, 1996). This study contributes to that area by presenting these women's description of their 'symptoms' and some of the consequences of these characteristics. Some of the women described characteristics similar to the Inattention criteria of the DSM-IV that included being easily distracted, and having difficulty with organization, sustaining attention, following through on instructions, and finishing tasks. 
It is the hope of this researcher that the findings of this study contribute toward the elimination of stereotypical attitudes toward women university students diagnosed with ADD. The danger of analyzing the data as a whole is the assumption of similarity (DeMarco, Campbell, \& Wuest, 1993). However, the exemplars that are provided demonstrate the differences in the expression of the disorder and in the experience of these women.

The limitations of this study are related to issues of methodology of the selected approach. The themes are based on an in-depth understanding of eight women, situated in a particular time and place. Therefore, they cannot be generalized with confidence beyond these participants. As well, the constraints of the wording of the research question must be acknowledged and may have unintentionally limited the women's responses.

Another important aspect of this study is not in the answers but also in the questions it generates (Kaschak, 1992). Here is one question it raised for me: "Is this experience unique to women university students diagnosed with ADD?" Similar research on the experience of women homemakers, women in the workforce, and male university students diagnosed with ADD would represent steps toward answering this question.

The participants expressed their positive regard for the research process. The process is respectful by valuing others' experience and expertise.

\section{SUMMARY}

This article presented some of the educational issues reported by women university students diagnosed with ADD and the strategies they employed to help them manage their difficulties. There is a growing body of literature on adult ADD, and this study contributes to that area by presenting these women's description of their 'symptoms' and some of the consequences of these characteristics. Another purpose of this study was to provide a venue for these women's voices because it is from their voices that we can learn. I heard the need for more education, awareness, and understanding of this 'invisible' disability, on the part of both faculty and students, including those students diagnosed with the disorder. I heard the need for more effective communication between faculty and 
students. I heard the need for more self-advocacy skills and learning strategies. I heard the need for more postsecondary preparation.

The experience of women university students diagnosed with ADD is clearly an issue worthy of further study. Further study would benefit similar women, and professionals in mental health and educational fields who support and provide services to these individuals. These women's voices can inform professionals about the effects of the characteristics known as ADD and about the meaning of their lived experience. The only way to know others as individuals is by speaking with them, not about them (Gadow, 1990).

\section{Notes}

1 The women's names are pseudonyms and all other identifying information has been changed.

\section{References}

Biederman, J., Faraone, S., Spencer, T., Wilens, T., Mick, E., \& Lapey, K. (1994). Gender differences in a sample of adults with Attention Deficit Hyperactivity Disorder. Psychiatry Research, 53(13), 13-29.

Cantwell, D.P. (1996). Attention Deficit Disorder: A review of the past 10 years. Journal of the American Academy of Child \& Adolescent Psychiatry, 35(8), 978-987.

Dwyer, S.L.C. (1998). The experience of women university students diagnosed with Attention-Deficit Disorder. Unpublished doctoral dissertation, The University of Calgary, Calgary, AB, Canada.

Ellis, C., \& Flaherty, M.G. (1992). An agenda for the interpretation of lived experience. In C. Ellis \& M.G. Flaherty (Eds.), Investigating subjectivity: Research on lived experience (pp. 1-13). Newbury Park, CA: Sage Publications.

Fischer, M. (1997). Persistence of ADHD into adulthood: It depends on whom you ask. The ADHD Report, 5(4), 8-10. 
Gadow, S. (1990). Response to "Personal knowing: Evolving research and practice". Scholarly Inquiry for Nursing Practice: An International Journal, $4(2), 167-170$.

Giroux, H.A., \& McLaren, P. (1992). Writing from the margins: Geographies of identity, pedagogy, and power. Journal of Education, 174(1), 7-30.

Hayes, E., \& Flannery, D.D. (1995). Adult women's learning in higher education: A critical review of scholarship. Initiatives, 57(1), 29-37.

Kaschak, E. (1992). Engendered lives: A new psychology of women's experience. New York, NY: Basic Books.

Kvale, S. (1996). InterViews: An introduction to qualitative research interviewing. Thousand Oaks, CA: Sage Publications.

Laidlaw, T.A., \& Malmo, C. (1990). Introduction: Feminist therapy and psychological healing. In T.A. Laidlaw, C. Malmo \& Associates (Eds.), Healing voices: Feminist approaches to therapy with women (pp. 1-12). San Francisco, CA: Jossey-Bass Pub.

Lloyd, B., Ennis, F., \& Alkinson, T. (1994). The power of women-positive literacy work: Program-based action research. Halifax, NS: Fernwood Publishing.

Lofland, J., \& Lofland, L.H. (1995). Analyzing social settings: A guide to qualitative observation and analysis. San Francisco, CA: Wadsworth Publishing Co.

Maykut, P., \& Morehouse, R. (1994). Beginning qualitative research: A philosophic and practical guide. Washington, DC: The Falmer Press.

McEvoy, M., \& Daniluk, J. (1995). Wounds to the soul: The experiences of aboriginal women survivors of sexual abuse. Canadian Psychology, 36(3), 221-235.

Miller, N.K. (1991). Getting personal: Feminist occasions and other autobiographical acts. New York, NY: Routledge.

Morse, J.M. (1995). The significance of saturation (Editorial). Qualitative Health Research, 5(2), 147-149.

Osborne, J.W. (1990). Some basic existential-phenomenological research methodology for counsellors. Canadian Journal of Counselling, 24(2), 79-91.

Osborne, J.W. (1994). Some similarities and differences among phenomenological and other methods of psychological qualitative research. Canada Psychology, 35(2), 167-189.

Polkinghorne, D. (1989). Phenomenological research methods. In R. Valle \& S. Halling (Eds.), Existential-phenomenological alternatives for psychology (pp. 41-60). New York, NY: Plenum. 
Pyke, S.W. (1997). Education and the "woman question". Canadian Psychology, 38(3), 154-163.

Ray, M. (1990). Phenomenological method for nursing research. In N.L. Chaska (Ed.), The nursing profession: Turning points (pp. 173-179). St. Louis, MO: C.V. Mosby Co.

Richard, M.M. (1994). College and university students with ADHD. The ADHD Report, 2(6), 4-6.

Ryan, W. (1971). Blaming the victim. New York, NY: Vintage Books.

Schaughency, E., McGee, R., Raja, S., Feehan, M., \& Silva, P. (1994). Self-reported inattention, impulsivity and hyperactivity at ages 15 and 18 years in the general population. Journal of the American Academy of Child and Adolescent Psychiatry, 33(2), 173-184.

Solden, S. (1995). Women with Attention Deficit Disorder: Embracing disorganization at home and in the workplace. Grass Valley, CA: Underwood Books.

Stainback, S., \& Stainback, W. (1988). Understanding and conducting qualitative research. Dubuque, IA: Kendall/Hunt Publishing Co.

Tesch, R. (1987). Emerging themes: How researchers discover them. Paper presented at the Sixth International Human Science Research Conference, Ottawa, ON.

Weiss, L. (1992). The Attention Deficit Disorder in adults. Dallas, TX: Taylor Pub. Co.

West, M., Kregel, J., Getzel, E.E., Zhu, M., Ipsen, S.M., \& Martin, W.D. (1993). Beyond Section 504: Satisfaction and empowerment of students with disabilities in higher education. Exceptional Children, 59(5), 456-467.

Weyandt, L.L. (1995). Reported prevalence of attentional difficulties in a general sample of college students. Journal of Psychopathology and Behavioral Assessment, 17, 293-304.

van Manen, M. (1990). Researching lived experience: Human science for an action sensitive pedagogy. London, $\mathrm{ON}$ : The Althouse Press. 